verine, ${ }^{10}$ and phenoxybenzamine may possibly have a role in diagnostic procedures for erectile dysfunction. None of the drugs, however, should be recommended yet for general therapeutical use.

This work was supported by grants from the Danish Hospital Foundation for Medical Research, region of Copenhagen, the Faroe Islands, and Greenland; the Danish Medical Research Council; P Carl Petersen's fund; Novo's fund; Carl J Becker's fund; and King Christian X's fund.

\section{References}

' Fahrenkrug J. Vasoactive intestinal polypeptide, measurement, distribu tion and putative neurotransmitter function. Digestion 1979;19:149-69.

2 Ottesen B. Vasoactive intestinal polypeptide (VIP) as a neurotransmitter in the female genital tract. Am $\mathcal{F}$ Obstet Gynecol 1983;147:208-24:

${ }^{3}$ Klinge E, Sjöstrand NO. Comparative study of some isolated mammalian smooth muscle effectors of penile erection. Acta Physiol Scand 1977; 100:354-67.

4 Sjöstrand NO, Klinge E. Principal mechanisms controlling penile retraction and protrusion in rabbits. Acta. Physiol Scand 1979;106:199-214.

5 Wagner G, Brindley GS. The effect of atropine, alpha and beta blockers on human penile erection: a controlled pilot study. In: Zorgniotti AW, Rossi G, eds. Vasculogenic impotence. Proceedings of the first international conference on corpus cavernosum revascularization. Springfield: Charles $C$ Thomas, 1980:77-81.
- Wagner G, Green R. Impotence, physiological, psychological, surgical diagnosis and treatment. New York: Plenum Press, 1981.

' Polak JM, Gu J, Mina S, Bloom SR. VIPergic nerves in the penis. Lancet 1981 ;ii:217-9.

8 Willis E, Ottesen B, Fahrenkrug J, Sundler F, Wagner G. Vasoactive intestinal polypeptide as a possible neurotransmitter in penile erection. Acta Physiol Scand 1981;113:545-7.

- Willis E, Ottesen B, Wagner G, Sundler F, Fahrenkrug J. Vasoactive intestinal polypeptide (VIP) as a putative neurotransmitter in penile erection. Life Sci 1983;33:383-91.

10 Virag R. Intracavernous injection of papaverine for erectile failure. Lancet 1982 ;ii:938.

11 Virag R. Artificial erection in the diagnosis and treatment of impotence. Urology (in press)

12 Fahrenkrug J, Schaffalitzky de Muckadell OB. Radioimmunoassay of vasoactive intestinal polypeptide (VIP) in plasma. F Lab Clin Med 1977;89:1379-88.

13 Wagner G, Uhrenholdt A. Blood flow measurement by the clearance method in the human corpus cavernosum in the flaccid and erect states. In: Zorgniotti AW, Rossi G, eds. Vasculogenic ímpotence. Proceedings of the first international conference on corpus cavernosum revascularization. Springfield: Charles C Thomas, 1980:41-6.

14 Mutt V, Said SI. Structure of the porcine vasoactive intestinal octacosapeptide. The amino-acid sequence. Use of kallikrein in its determination. Eur f Biochem 1974;42:581-9.

15 Goldstein I, Krane RJ, Ottesen B, Fahrenkrug J, Wagner G. Vasoactive intestinal polypeptide (VIP) release during pelvic nerve stimulated penile erections. Invest Urol (in press).

${ }^{16}$ Brindley GS. Cavernosal alphá blockade: a new technique for investigating and treating erectile impotence. Br $\mathcal{F}$ Psychiatry 1983;143:332-7.

(Accepted 10 November 1983)

\title{
Blood pressure control during weight reduction in obese hypertensive men: separate effects of sodium and energy restriction
}

\author{
BJÖRN FAGERBERG， OVE K ANDERSSON， BJÖRN ISAKSSON， PER BJÖRNTORP
}

\begin{abstract}
The separate and combined effects of dietary energy and sodium restriction on regulation of blood pressure were investigated in 30 middle aged obese men with essential hypertension attending the outpatient department. In group $1(n=15)$ a basal period with no dietary restriction wias followed by a period taking an energy reduced diet $(5 \cdot 1 \mathrm{MJ} ; 1230 \mathrm{kcal})$, the sodium intake being supplemented and hence unchanged (1:ErSn). In group 2 $(n=15)$ the basal period preceded a control period with no intervention, which was followed by taking a diet restricted in energy (5.1 $\mathrm{MJ} ; 1220 \mathrm{kcal})$ and sodium (2:ErSr). During period 1:ErSn there were reductions in heart rate and urinary noradrenaline output but not in systolic or diastolic blood pressure. Body weight decreased by 4.9-11.7 $\mathrm{kg}$ and urinary sodium excretion
\end{abstract}

\footnotetext{
Hypertension Unit, Department of Medicine I, Sahlgren's Hospital, University of Gothenburg, S-413 45 Göteborg, Sweden

BJORN FAGERBERG, MD, resident

OVE K ANDERSSON, MD, PHD, associate professor

PER BJORNTORP, MD, PHD, professor
}

Department of Clinical Nutrition, Sahlgren's Hospital, University of Gothenburg, Sweden

BJORN ISAKSSON, MD, PHD, professor

Correspondence and requests for reprints to: Dr Björn Fagerberg. did not change. In period 2:ErSr urinary sodium output was reduced by 81.4 (SEM 17.8) $\mathrm{mmol}(\mathrm{mEq}) / 24 \mathrm{~h}$ and there was a weight loss of 8.2 (SEM 0.7) kg. Systolic and diastolic blood pressures fell significantly, as did the heart rate and urinary noradrenaline excretion.

These results show that in hypertensive obese men a moderate weight reducing diet decreases indices of sympathetic nervous system activity. Reduction of blood pressure to the normotensive range was observed only when there was a concomitant restriction of sodium intake.

\section{Introduction}

Reducing weight by decreasing the energy intake lowers the blood pressure in most obese hypertensive patients. ${ }^{1-8}$ Nevertheless, weight reduction has not been widely considered as a possible alternative to drug treatment of hypertension, probably owing to the disappointing long term results of weight reduction in obesity. ${ }^{\circ}$ Also the concomitant decrease in dietary salt may have been thought to be responsible for the hypotensive effect of weight loss. ${ }^{10}$ In recent years, however, several long term studies $^{11} 12$ have shown a convincing effect of weight reduction on blood pressure control in mild hypertension. In addition, some suggest that the weight reduction by itself and not the restriction of salt is the factor responsible for the blood pressure lowering effect, ${ }^{\prime} \gamma$ although this remains controversial. ${ }^{13}$ As an alternative mechanism of reduction in blood pressure with weight loss some authors have reported a hypotensive effect of 
low carbohydrate energy restricted diets, probably mediated by decreased sympathetic nervous system activity. ${ }^{714} 15$

We set out to study two factors that might affect the mechanisms by which diet induced weight loss decreases blood pressure. The study was designed to separate the effects of sodium and energy restriction on the expected hypotensive response. Other factors which might influence blood pressure regulation-namely, physical activity and alcohol consumption -were controlled in order that they would remain unchanged.

\section{Patients and methods}

Thirty four middle aged men were recruited for the study. Criteria for inclusion were that they were $20-40 \%$ overweight, ${ }^{16}$ that their diastolic blood pressure was above $94 \mathrm{~mm} \mathrm{Hg}$ and below $115 \mathrm{~mm} \mathrm{Hg}$; that they were not receiving medication for hypertension; and that a standard clinical examination ${ }^{17}$ showed no evidence of abnormality. All patients gave informed consent, and the local ethical committee approved the protocol. During the study the patients were repeatedly instructed not to change their alcohol intake, smoking habit, or physical activity.

Resting auscultatory blood pressure was recorded three times after 60 minutes' supine rest with a cuff $(16 \times 36 \mathrm{~cm})$ connected to a mercury manometer, the diastolic pressure being recorded as phase $V$. Resting intra-arterial blood pressure was measured with a pressure transducer connected to a catheter in the left brachial artery and calculated as the mean of three recordings which were obtained simultaneously with the auscultatory assessments. Resting heart rate was calculated from the electrocardiogram or by palpation of the radial pulse.

Body weight was measured at the end of each study period with a level balance scale and with the patients wearing trousers. Body mass index was calculated as body weight $(\mathrm{kg}) / \mathrm{height}(\mathrm{m})^{2}{ }^{18}$ Body fat was estimated from measurements of weight, height, total body water, and total body potassium, as described. ${ }^{19}$ The sodium and potassium concentrations in blood and urine were determined by flame photometry. Twenty four hour urinary noradrenaline output was determined by a method originally described by von Euler and Lishajko ${ }^{20}$ and calculated as the mean of two collections.

Means, standard error of the mean (SEM), and correlation coefficients $(r)$ were calculated by standard methods. Differences in means within and between groups were tested with Student's $t$ test. Statistical significance was accepted as $p<0 \cdot 05$. Results are expressed as means and SEM.

\section{STUDY DESIGN}

The patients were allocated at random to group 1 or group 2. Initially both groups underwent a basal period (three to four weeks), when they were asked not to change any of their habits. Body weight, height, total body water, and total blood potassium were measured. The subjects recorded their diet for four days. Four 24 hour collections of urine were obtained for determination of electrolyte and catecholamine concentrations. At the end of the period the resting heart rate and blood pressure were recorded. Subjects attended the laboratory at 8 am after a small, standardised breakfast. Blood was drawn from an indwelling cubital vein catheter for determination of serum electrolyte concentrations. Finally, the patients answered questionnaires on their alcohol intake and degree of physical activity during the past month.

In group 1 a dietitian presoribed an energy restricted diet (Er) with unchanged sodium intake (Sn) for 12 weeks (period $1: \mathrm{ErSn}$ ). The dietary instructions were based on a standardised diet adjusted to individual needs (15-20\% of energy taken as protein, $25-30 \%$ fat, and $50-60 \%$ carbohydrates) and aimed at a weight reduction of $1 \mathrm{~kg}$ a week.

The habitual daily sodium intake was judged from the mean of the four previous 24 hour urinary sodium outputs plus $10 \mathrm{mmol}(10 \mathrm{mEq})$ for extrarenal loss. ${ }^{21}$ In order to maintain the salt intake at this level the energy reduced diet was composed of low sodium foods. Table salt in preweighed packets and sodium tablets (Natriumklorid $0.5 \mathrm{~g}$; ACO, Sweden) were added. The patients saw the dietitian every two to three weeks. Adherence to the diet in each period was checked by interview or four day dietary records and four 24 hour urine sodium determinations. Patients who had difficulty with the diet had the instructions modified. At the end of the period the final measurements of the basal period were repeated.
The subjects in group 2 entered a control period (four weeks) after the basal period, during which they continued with their normal energy (En) and sodium (Sn) intake (period $2: \mathrm{EnSn}$ ). The same measurements were performed as in period 1:ErSn, with the exception that intra-arterial blood pressure was not recorded. Finally, group 2 was advised on both energy (Er) and sodium (Sr) restriction by the dietitian (period 2:ErSr) for nine weeks. The instructions aimed at a dietary composition comparable to that in period $1: \mathrm{ErSn}$ with the difference that sodium intake was restricted to below $100 \mathrm{mmol} / 24 \mathrm{~h}$. The final measurements were identical with those of the basal period.

\section{Results}

Four patients were excluded owing to non-compliance. The final series consisted of 30 patients, with 15 in each group. For technical reasons intra-arterial blood pressure was recorded in 13 patients in group 1 and 10 in group 2 . There were no differences between the groups either in any clinical variable examined (table I) or in their urinary excretion of sodium, potassium, or noradrenaline (table II).

Ten subjects in each group were judged to have stage 2 hypertension and five to have stage 1 (WHO classification). ${ }^{22}$ Five subjects in group 1 and seven in group 2 had a family history of hypertension. Obesity in one or both parents was found in 10 patients in group 1 and 11 in group 2.

TABLE I-Clinical characteristics during basal period, when taking normal diet. (Mean values expressed with SEM in parentheses)

\begin{tabular}{lcc}
\hline & Group 1 & Group 2 \\
\hline No of subjects (all men) & 15 & 15 \\
Mean age (years) & $51 \cdot 4(1 \cdot 3)$ & $50 \cdot 8(0 \cdot 8)$ \\
Mean body weight $(\mathrm{kg})$ & $97 \cdot 3(2 \cdot 5)$ & $97 \cdot 6(2 \cdot 3)$ \\
Mean body mass index $\left(\mathrm{kg} / \mathrm{m}^{2}\right)$ & $30 \cdot 6(0 \cdot 7)$ & $30 \cdot 9(0 \cdot 7)$ \\
Mean body fat (kg) & $25.5(2 \cdot 0)$ & $27 \cdot 1(1 \cdot 5)$ \\
Mean energy intake $(\mathrm{MJ} / 24 \mathrm{~h})$ & $9 \cdot 82(0 \cdot 42)$ & $9 \cdot 78(0 \cdot 42)$ \\
Mean initial blood pressure (mm Hg): & $152 \cdot 4(2 \cdot 2)$ & $152 \cdot 8(2 \cdot 6)$ \\
Systolic & $101 \cdot 5(1 \cdot 3)$ & $100 \cdot 5(1 \cdot 3)$ \\
Diastolic & $73 \cdot 3(1 \cdot 8)$ & $71 \cdot 5(1 \cdot 7)$ \\
Mean heart rate (beats/min) & 3 & 3 \\
No with left ventricular enlargement (as & 7 & 8 \\
judged radiographically) & 5 with eye ground changes* & $5 / 10$ \\
No with stage 1/stage 2 hypertension (WHO & $5 / 10$ & \\
classification) & & \\
\hline
\end{tabular}

*Fundus hypertonicus I, diagnosed according to classification of Keith-Wagener.

Conversion: SI to traditional units-Energy intake: $4 \cdot 18 \mathrm{MJ}=1000 \mathrm{kcal}$.

In period $1:$ ErSn the weight loss ranged from 4.9 to $11.7 \mathrm{~kg}$ and the urinary output of sodium and potassium remained unchanged as compared with basal values (table II). The dietary histories showed a daily energy intake of $5 \cdot 1$ (SEM 0.16) MJ (1230 (40) kcal), consisting of 26.5 (SEM $1 \cdot 1$ ) \% of energy being taken as fat and with a polyunsaturated to saturated fat ratio of 0.24 (SEM 0.005). There were no significant changes in blood pressure compared with prediet measurements (table II) or values in the control group (period 2:EnSn). Heart rate and urinary noradrenaline output, however, significantly decreased (table II).

In group 2 during the control period ( $2: \mathrm{EnSn})$ there was a significant reduction in systolic blood pressure but no other change (table II). Simultaneous energy and salt restriction (2: $\mathrm{ErSr})$ was associated with a mean weight loss of $8 \cdot 2(0 \cdot 7) \mathrm{kg}$ (range $4 \cdot 2-15 \cdot 0 \mathrm{~kg}$ ) and a reduction in urinary sodium output of $81.4(17.8) \mathrm{mmol} / 24 \mathrm{~h}$ (table II). The urinary potassium excretion did not change, and consequently there was a significant reduction of the sodium to potassium ratio (table II). The daily energy intake was $5 \cdot 1(0 \cdot 21)$ MJ $(1220$ (50) $\mathrm{kcal}$ ) as judged from the dietary histories, which also showed that fat provided $26.3(1.2) \%$ of the intake of energy with a polyunsaturated to saturated fat ratio of $0.24(0.01)$, statistically not significantly different from period $1: \mathrm{ErSn}$.

Systolic and diastolic blood pressures fell by $7 \cdot 1 \quad(2 \cdot 3 \mathrm{~mm} \mathrm{Hg}$ $(p<0.05)$ and $7.2(2.5) \mathrm{mm} \mathrm{Hg}(p<0.05)$ respectively. There were also significant reductions in heart rate and urinary noradrenaline excretion as compared with the control period (table II). There were no changes in the serum concentrations of sodium and potassium. The questionnaires disclosed a highly varying alcohol consumption, which did not, however, change significantly in any group during the study. No changes in physical activity were recorded.

Auscultatory and intra-arterial systolic blood pressures showed a 
high correlation $(r=0.94 ; p<0.001)$, but that for diastolic pressures $(r=0.84 ; p<0.01)$ was less (figure). The difference between auscultatory and intra-arterial systolic pressures before dieting was -1.6 (1.6) $\mathrm{mm} \mathrm{Hg}$ and after dieting $4.3(1.9) \mathrm{mm} \mathrm{Hg}(\mathrm{p}<0.05)$, the auscultatory pressure being somewhat overestimated after dieting.

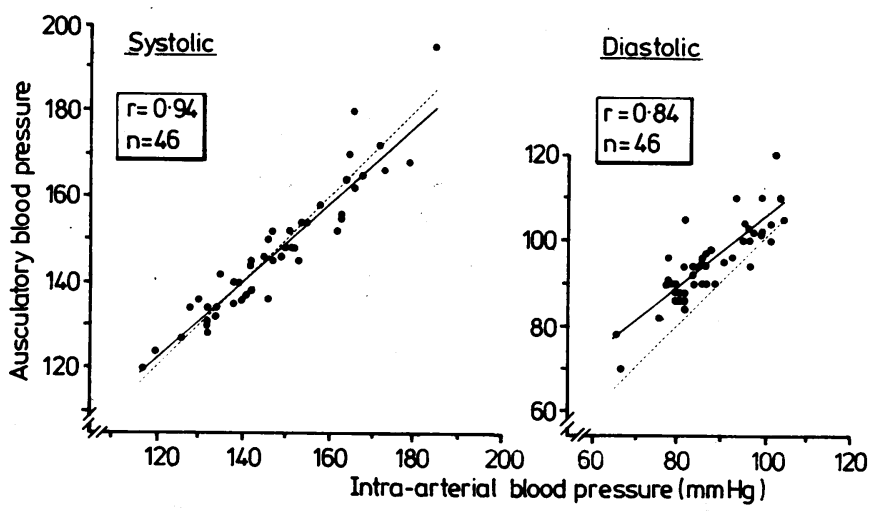

Comparison between intra-arterial and auscultatory blood pressures in 23 hypertensive obese men examined twice (solid line). groups. Regarding confounding factors, there is evidence that an increase in polyunsaturated to saturated fat ratio in the diet may lower blood pressure ${ }^{25}{ }^{26}$ and that changes in alcohol intake $^{27}$ or physical activity may also affect blood pressure. ${ }^{28}$ We, however, found no suggestion of a differing intake of fat when comparing the weight reducing diets of the two groups, and examination of the questionnaires showed no differences in alcohol intake or exercise within or between the groups.

The reduction in arm circumference during weight loss may introduce an artefact in the auscultatory measurements of blood pressure.29 We tried to overcome this by measuring intra-arterial and auscultatory blood pressures simultaneously. We found that after weight reduction the auscultatory recordings tended to overestimate the systolic blood pressure, thus disguising any hypotensive response to dieting. The auscultatory diastolic blood pressure, on the other hand, was consistently overestimated despite the wide cuff used. The correlation between intra-arterial and auscultatory recordings was high. The same nurse performed the indirect blood pressure recordings throughout, thereby avoiding change in observer error, which is important since some measurements included only auscultatory recordings.

Blood pressure varies widely and may show a systematic

TABLE II-Changes in body weight, urinary excretion of electrolytes and noradrenaline, blood pressure, heart rate, and alcohol intake during energy but not sodium restriction (1:ErSn), normal energy and sodium intake (2:EnSn), and energy and sodium restriction (2:ErSr). (Values are means (SEM in parentheses)

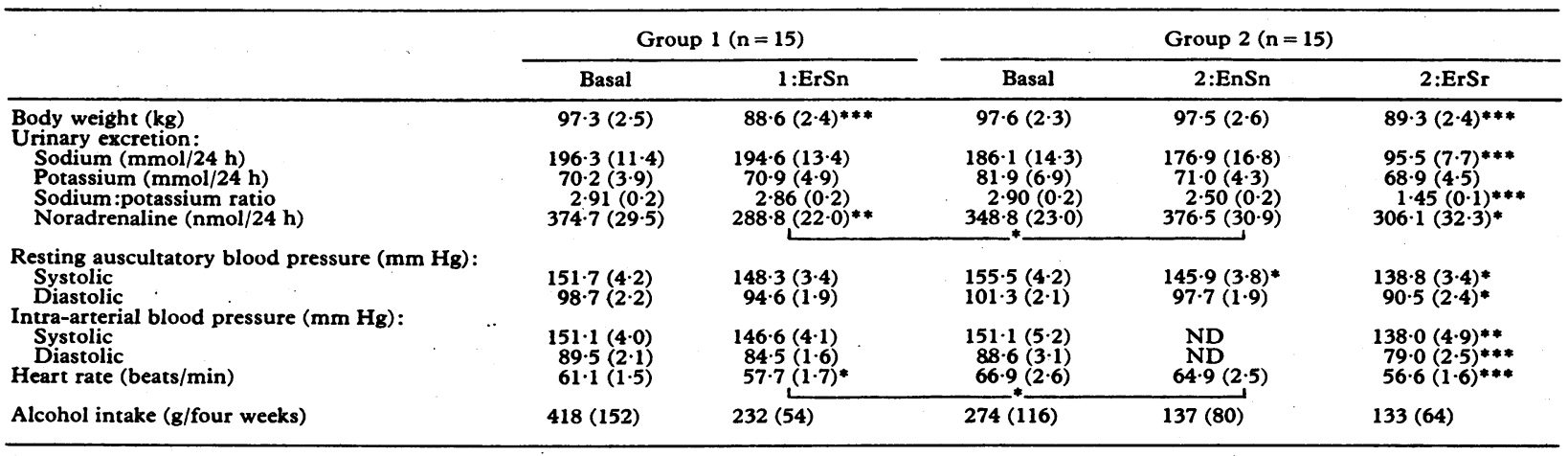

ND $=$ Not done.

Compared with previous value: *p $<0.05 ; * * p<0.01 ; * * 0<0.001$

Conversion: SI to traditional units-Sodium and potassium: $1 \mathrm{mmol}=1 \mathrm{mEq}$. Noradrenaline: $1 \mathrm{nmol} \approx 170 \mathrm{ng}$.

The corresponding differences between auscultatory and intraarterial diastolic pressures were $8.0(1 \cdot 2) \mathrm{mm} \mathrm{Hg}$ and $9.5(1 \cdot 1) \mathrm{mm} \mathrm{Hg}$ (NS).

In group 2 there were positive correlations between the decrements in mean intra-arterial pressure and body weight $(\mathrm{r}=0.61 ; \mathrm{p}<0.05)$ and decrements in mean intra-arterial pressure and the decrease in sodium output $(r=0.73 ; p<0.01)$.

\section{Discussion}

Making valid conclusions from these results depends on the comparability of the study groups, the subjects' adherence to the dietary regimen, and the control of confounding factors. The selection of similar study groups should be extended to include hereditary factors, as there is increasing evidence of genetic subgroups in hypertensive populations with respect to a family history of high blood pressure and obesity. ${ }^{23} 24$ In our study the randomisation apparently resulted in an even distribution for background variables. Hence the study groups were comparable with regard to hereditary factors, age, body weight, body fat, blood pressure, and distribution of organ damage secondary to hypertension. Furthermore, the changes in body weight, dietary records, and urinary sodium estimations indicated good compliance with the dietary instructions in both fall during the initial period of ambulatory supervision, which may confound the assessment of response to treatment. ${ }^{80}{ }^{31}$ It has been shown that after one hour's supine rest blood pressure decreases more than $20 \%$ compared with the initial casual reading and that this resting blood pressure correlates better with indices of hypertensive heart disease than do casual recordings. ${ }^{32}$ This may suggest a smaller degree of variability but does not exclude the influence of habituation and regression towards the mean as factors that might bias the results in long term intervention studies. Our measurements of resting blood pressure showed a reduction of systolic pressure during the control period in group 2, which emphasises the importance of having identical groups of subjects in studies of blood pressure control.

Our study shows that dietary induced weight loss is associated with a reduction in blood pressure to the normotensive range in hypertensive obese patients only if there is a concomitant restriction of sodium intake. This accords with the results of a smaller and uncontrolled study by Dahl et al, who investigated patients in metabolic ward conditions with a regimen similar to that used by us. ${ }^{10}$ The often cited outpatient study by Reisin and coworkers gave results conflicting with our own; they suggested that reduced energy intake and weight loss by themselves lead to a reduction of blood pressure independent of dietary sodium intake. ${ }^{6}$ Their study, however, has been criticised for insufficient control of sodium balance, ${ }^{13}$ and we find that 
conventional weight reducing diets with a proved hypotensive effect are indeed reduced in sodium content. ${ }^{15}$

Evidence suggests that severe energy restriction causes reduction of the blood pressure, independent of sodium intake, probably by an effect on the sympathetic nervous system activity. ${ }^{714}$ 33 These results, however, may not be contradictory to our own, since in the cited studies the patients were receiving semistarvation diets of 1.3-1.7 MJ (300-400 kcal) a day, presumably leading to adaptive mechanisms other than in our patients, who ate $5.0 \mathrm{MJ}$ (1200 kcal) a day. Interestingly, we also found indications of diet induced reduction of sympathetic nervous system activity, the urinary excretion of noradrenaline and the heart rate decreasing in both groups during low energy intake. This, however, was associated with reduction of the blood pressure only when sodium intake also was restricted.

A high potassium intake and a low urinary sodium to potassium ratio is reportedly associated with a lowering of blood pressure. $^{34}$ ss During the period with sodium restriction and blood pressure reduction our patients showed a decreased sodium to potassium ratio. Although they did not increase their potassium intake, we cannot exclude the possibility that this altered ratio was related to the observed changes in blood pressure.

Other studies have given conflicting results concerning the effect of moderate sodium restriction on blood pressure control. ${ }^{31}$ Against that background it is impossible to conclude whether our observation of a fall in blood pressure during weight reduction was an effect of sodium restriction only, or if the concomitant decrease in sympathetic nervous system activity had an additive effect on the hypotensive response; the latter, however, seems reasonable.

This project was supported by a grant from the Swedish National Association Against Heart and Chest Diseases and from the Swedish Medical Research Council (project 19X-570). Financial support was also received from the Gotteborg Medical Society.

Measurements of urinary noradrenaline were performed by the department of clinical chemistry and total body potassium determined by the department of radiation physics, Sahlgren's Hospital. We also acknowledge the valuable contributions of dietitian Irene Hugosson, laboratory technician Gertrud Hansson, and Leif Hultin for preparing the manuscript.

\section{References}

${ }^{1}$ Chiang BN, Perlman LV, Epstein HF. Overweight and hypertension. A review. Circulation 1969;39:403-21.

2 Genuth SM, Catro JH, Vertes V. Weight reduction in obesity by outpatient semistarvation. $\mathcal{F} A M A 1974$;230:987-91.

${ }^{3}$ Heyden S, Tyroler HA, Hames CG, et al. Diet treatment of obese hypertensives. Clinical Science and Molecular Medicine 1973;45:209-12s.

4 Lindner PG, Blackburn GL. Multidisciplinary approach to obesity utilizing fasting modified to protein-sparing therapy. Obesity and Bariatric Medicine 1976;5:198-216.

5 Heyden S. The working man's diet. Effect of weight reduction in obese patients with hypertension, diabetes, hyperuricemia and hyperlipidemia. Nutr Metab $1978 ; 22: 141-59$.

- Reisin E, Abel R, Modan M, Silverberg S, Eliahou HE, Modan B. Effect of weight loss without salt restriction on the reduction of blood pressure in overweight hypertensive patients. $N$ Engl $f$ Med 1978; 298:1-6.

7 Tuck ML, Sowers J, Dornfield L, Kledzik G, Maxwell M. The effect of weight reduction on blood pressure, plasma renin activity, and plasma aldosterone levels in obese patients. N Engl f Med 1981 ;304:930-3.

- Ramsay LE, Ramsay MH, Hettiarachchi J, Davies DL, Winchester J. Weight reduction in a blood pressure clinic. $\mathrm{Br}$ Med $\mathcal{F}$ 1978;ii :244-5.

- Stunkard AJ. The management of obesity. NY State $\mathcal{F}$ Med. 1958;58: 79-87.

10 Dahl LK, Silver L, Christie RW. Role of salt in the fall of blood pressure accompanying reduction of obesity. $N$ Engl $\mathcal{F}$ Med 1958;258:1186-92.

11 Stamler J, Farinaro E, Majonnier LM, Hall Y, Moss D, Stamler R. Prevention and control of hypertension by nutritional-hygienic means. f AMA 1980;243:1819-23.

12 Eliahou HE, Jaina A, Gaar T, Schochat J, Modan M. Body weight reduction necessary to attain normotension in the overweight hypertensive patient. Int $\mathcal{Y}$ Obes.1981;5, suppl 1:157-63.

13 Heyden S, Nelius SJ, Hames CG. Obesity, salt intake, and hypertension. Fournal of Cardiovascular Medicine 1980;5:987-9, 993-4.

14 Jung RT, Shetty PS, Barrand M, Callingham BA, James WPT. Autonomic responsiveness in obesity with and without hypertension. Int $\mathcal{f}$ Obes 1981 ;5, suppl $1: 73-8$.

15 Fagerberg B, Andersson O, Nilsson U, Hedner T, Isaksson B, Björntorp $P$. Weight reducing diets: role of carbohydrates on sympathetic nervous activity and hypotensive response. Int $\mathcal{F}$ Obes (in press).

${ }^{16}$ Lindberg W, Natvig H, Rygh A, Svendsen K. Hoyde- og vektundersokelser hos voksne menn og kvinner. Forslag till nye norske hoydevektnormer. Tidsskr Nor Laegeforen 1956;76:361-8.

17 Andersson O, Berglund G, Hansson L, et al. Organization and efficacy of an out-patient hypertension clinic. Acta Med Scand 1978;203: 391-8.

18 Larson B. Obesity. A population study of men with special reference to development and the consequences for health. University of Göteborg, 1978. Thesis.

${ }^{19}$ Bruce $\AA$, Andersson $M$, Arvidsson B, Isaksson B. Body composition Prediction of normal body potassium, body water, and body fat in adults on the basis of body height, body weight and age. Scand $\mathcal{F}$ Clin Lab Invest 1980;40:461-73.

* Von Euler US, Lishajko F. The estimation of catecholamines in urine. Acta Physiol Scand 1959;45:122-31.

${ }^{21}$ Isaksson B, Lindholm B, Sjögren B. Dermal losses of nutrients and their significance for human metabolic balance studies. Acta Med Scand $1966 ; 179$, suppl 445:416-20.

22 World Health Organisation. Arterial hypertension. Geneva: WHO, 1978.

${ }^{23}$ Altschul AA, Grommet JK. Sodium intake and sodium sensitivity. Nutr Rev 1980;38:393-402.

24 Simic BS, Dimitrijevic D, Sekulovic I, Trajkovic L. The relation of obesity onset age and the effect of reducing diet on blood pressure. Acta Med Iugosl 1981 ;35:95-102.

25 Puska P, Iacono JM, Nissinen A, et al. Controlled randomised trial of the effect of dietary fat on blood pressure. Lancet 1983;i:1-5.

${ }^{26}$ Iacono JM, Judd JT, Marshall MW, et al. The role of dietary essential fatty acids and prostaglandins in reducing blood pressure. In: Holman RP, ed. Progress in lipid research. Vol 20. Oxford: Pergamon Press, $1981: 349-64$.

27 Criqui MH, Wallace RB, Mishkel M, Barrett-Connor E, Heiss G. Alcohol consumption and blood pressure. Hypertension $1981 ; 3: 557-65$.

${ }^{28}$ Krotkiewski M, Mandroukas K, Sjöström L, Sullivan L, Wetterqvist $H_{\text {, }}$ Björntorp P. Effects of long-term physical training on body fat, metabolism and blood pressure in obesity. Metabolism 1979;28:650-8.

29 Maxwell MH, Waks AU, Schroth PC, Karam M, Dornfield LP. Error in blood pressure measurement due to incorrect cuff size in obese patients. Lancet 1982 ;ii :33-6.

${ }^{30}$ Dunne JF. Variation of blood-pressure in untreated hypertensive outpatients. Lancet $1969 ; \mathrm{i}: 391-2$.

${ }^{31}$ Silman AJ, Locke C, Mitchell P, Humpherson P. Evaluation of the effectiveness of a low sodium diet in the treatment of mild to moderate hypertension. Lancet $1983 ; \mathrm{i}: 1179-82$.

32 Wikstrand J, Berglund G, Wilhelmsen L, Wallentin I. Orthogonal electrocardiogram, apex cardiogram and atrial sound in normotensive and hypertensive 50-year-old men. Br Heart $\mathcal{F}$ 1976;38:779-89.

${ }^{33}$ Sowers JR, Nyby M, Stern N, et al. Blood pressure and hormone changes associated with weight reduction in the obese. Hypertension 1982;4: 686-91.

${ }^{34}$ MacGregor GA, Smith SJ, Markandu ND, Banks RA, Saqnella GA. Moderate potassium supplementation in essential hypertension. Lancet 1982 ;ii:567-70.

35 Skrabal F, Auböck J, Hörgnagl H. Low sodium/high potassium diet for prevention of hypertension: probable mechanisms of action. Lancet 1981 ;ii :895-900.

(Accepted 13 October 1983)

ONE HUNDRED YEARS AGO Few comforts are left the poor who seek in their declining years the shelter of the workhouses; but one, which is prized by long habit, is the old woman's cup of tea made in her own teapot. From a recent police-court case, reported in the daily journals, it seems that poor women under sixty years of age are not allowed to have teapots and make their own tea. Even to have a little tea in their possession, to be made into the comforting beverage surreptitiously in drinking cans or any convenient vessel, is against the iron rule, it seems, of St Luke's workhouse. Surely this is carrying dietetic rules too far; "robbed of their beer," deprived of their tea, limited in their meat-food, the rule of the workhouse is made harder perhaps than it need be; at all events, we think the custom universally adopted in hospitals might be allowed in workhouses, namely, of allowing each inmate to have his or her own little teapot and small store of tea. To those who have lost all, even a small possession is of great value, and to those who have been accustomed to live chiefly on tea, the boiled beverage that goes by that name in workhouses must be peculiarly distasteful. We trust that the guardians of $\mathrm{St}$ Luke's workhouse will relax their rules in this respect. (British Medical fournal $1884 ; \mathrm{i}: 24$.) 